\title{
ESPAÇO DE CULTURA E ARTES COM ÊNFASE NO LIVRO FÍSICO E DIGITAL
}

\author{
Vitor Martinez Arruda Campos, Maria Alessandra Bacaro Boscoli
}

Universidade do Oeste Paulista - UNOESTE, Curso de Arquitetura e Urbanismo, Presidente Prudente, SP. E-mail: allyboscoli@gmail.com

\section{RESUMO}

A Implantação de um Espaço de Artes e Cultura em Presidente Prudente, visa acima de tudo, divulgar a cultura entre os jovens e as crianças, incentivando a educação, leitura e as artes. A implantação do espaço torna-se muito importante quando percebemos a realidade da juventude brasileira, o nível de cultura das gerações que vem surgindo. A defasagem cultural notável, que pode ser melhorada com esse projeto.

O espaço visa, integrar a cultura formal com a tecnologia que avança cada dia mais, através da inserção de elementos arquitetônicos e tecnológicos favoráveis a leitura e as artes. $O$ espaço propõe um traçado inovador, que possa ser identificado pela população como um edifício artístico e cultural, pela sua arquitetura moderna.

Palavras-chave: Artes; Cultura; Educação; Tecnologia; Juventude.

\section{CULTURE AND ARTS SPACE WITH EMPHASIS ON THE DIGITAL BOOK AND PHYSICAL}

\begin{abstract}
The Implementation of a Space Arts and Culture in Presidente Prudente, aims above all, spread the culture among young people and children, encouraging education, reading and the arts. The implementation of space becomes very important when we realize the reality of Brazilian youth , the level of culture of the generations that are emerging. The remarkable cultural gap that can be improved with this project .

The space aims to integrate formal culture with technology advancing every day more, by inserting architectural and technological elements favorable reading and the arts. Space proposes an innovative layout, which can be identified by the population as an artistic and cultural building for its modern architecture.

Keywords: Arts; Culture; Education; Technology; Youth.
\end{abstract}




\section{INTRODUÇÃO E OBJETIVO}

O trabalho apresentado vai nos mostrar que a cultura dos jovens brasileiros esta defasada, que as gerações atuais estão carentes de cultura, educação e artes. Que o incentivo para as gerações futuras é muito importante, para que se possa obter um nível de cultura inédito entre os jovens brasileiros, visando o poder de auto crítica, independência e criatividade. E que o futuro desse país pode ser melhor, se a educação for oferecida de forma séria e dedicada pelas autoridades.

Através do estudo da educação brasileira e de referências nacionais e internacionais, será elaborado um projeto cujo o objetivo é aproximar os jovens e a população em geral da educação, através dos livros, tecnologias e artes. Será criado um espaço físico, com tecnologias educacionais (computador, tablets, e-books, e-readers, etc.), afim de estabelecer um equilíbrio entre o real e o virtual, conceito muito forte hoje entre os jovens.

Serão apresentadas fundamentações teóricas, com o objetivo de identificar os possíveis impactos que esse edifício causará em Presidente Prudente, como: histórico, estético, social, cultural e econômico. O objetivo do projeto, é de perceber como os jovens irão se sentir atraídos pelo local, seja pela tecnologia, cores e eventos - proporcionando um espaço que atenda as necessidades contemporâneas do que é necessário para um local de aquisição de cultura, tanto pela leitura quanto as artes.

O conceito do projeto é proporcionar um espaço cultural, com ênfase no livro; e de como influenciar na cultura dos jovens brasileiros através desse espaço. Segundo Silva (1999, p. 70). "Não podemos deixar de assinalar o papel da biblioteca escolar na formação de personalidades críticas, criativas e dinâmicas. Com a diversidade de informações que a biblioteca escolar pode oferecer se dignamente instalada, os estudantes poderão tomar conhecimento de idéias diferentes ou mesmo divergentes daquelas transmitidas pelo professor, o que lhes poderá provocar inquietações e questionamentos, elementos indispensáveis ao desenvolvimento de uma educação emancipatória, ainda que insuficientes para livrar totalmente os alunos das influências do discurso dominante na escola."

Serão abordados, através da fundamentação teórica, as vantagens e desvantagens do livro digital em relação ao impresso. O que deve se atualizar e o que deve ser mantido. Termos como "e-books" e "e-readers" serão muito comentados, pois são os livros eletrônicos e os leitores eletrônicos, que nos dias atuais protagonizam grandes dicussões em relação a vida literária. Os centros culturais mais relevantes, nos apontam a importância desses espaços, criados para melhorar a interação entre as pessoas da sociedade. 


\section{METODOLOGIA}

A metodologia busca compreender como incentivar o tema abordado, através de estudos baseados em levantamentos bibliográficos.

\section{RESULTADOS}

Oferecer um espaço de Artes e Cultura na cidade de Presidente Prudente, com ênfase na educação. Promover a mudança na cultura dos jovens, projetando um espaço que atenda às necessidades contemporâneas do que é necessário para chamar a atenção das crianças, para que se interessem pelo universo da educação.

O espaço tem o objetivo de disseminar a cultura, e promover um novo mecanismo em relação aos livros, estabelecendo um equilíbrio entre o real e o digital.

Instigar a leitura e a cultura entre os jovens brasileiros, através de um projeto moderno e tecnológico, favorecendo além de tudo, todas as classes sociais. Trabalhar com a doação de livros antigos, para que se possa montar um acervo amplo e se possível, trabalhar em conjunto com a estante virtual (site de vendas de livros mais procurados), gerando assim, uma renda pra o espaço.

\section{DISCUSSÃO}

\subsection{Vantagens e desvantagens do livro eletrônico}

O fato que ocorre nos dias atuais, é que muitos autores e leitores têm se sentido atraídos pela facilidade de publicação e aquisição de arquivos digitais em forma de livros. Segundo Epstein (2002, p. 29) “Não se pode prever o futuro dessas tecnologias para o mercado editorial em detalhes, mas os seus efeitos gerais serão permitir aos leitores e aos escritores um acesso bem mais direto entre si do que o possível no passado e desafiar as editoras a reconhecerem a redução de suas funções e se adaptarem à nova realidade."

As editoras convencionais e as digitais, estão estabelecendo uma relação interessante pela comercialização dos livros. Obras impressas estão sendo vendidas como e-books, no formato digital; e livros digitais, vendidos impressos.

Quanto a rentabilidade a principal vantagem do e-book é a venda sobre demanda. Só se imprime o que é encomendado. Assim, as editoras se tornam mais livres para investir em outros autores, sem um risco de prejuízo no caso de rejeição.

Outro aspecto importante é que com os livros digitais, não há a preocupação com o potencial de venda de cada obra, não tendo que fazer a impressão em grandes lotes. Esse aspecto acaba deixando o editor mais livre, podendo fazer outras atividades como: o registro na Biblioteca 
Nacional, a digitação dos originais, a revisão gramatical, a digitalização das imagens, a criação do livro digital em formatos variados, a hospedagem dentro do site da editora, além da divulgação e distribuição.

A facilidade do armazenamento dos e-books, é algo que tem que ser contado como vantagem também - pois, a economia de espaço nas prateleiras acaba sendo enorme. Além da facilidade de transportá-los e transferi-los de um aparelho a outro.

A facilidade de publicação e edição dos livros digitais são bem maiores que um livro convencional, favorecendo os autores que não podem contratar os serviços de uma editora. Com a tecnologia, a velocidade de propagação de informação se tornou muito mais rápida e eficiente do que o alcance dos impressos.

Porém, têm também as suas desvantagens. Como o Brasil não é dos países mais justos, muitas pessoas não possuem condições de adquirir um hardware e a dificuldade de acesso à internet também atrapalha.

A grande maioria dos leitores hoje em dia ainda preferem os livros impressos, visto que muitos não se adptam a leitura digital devido ao estresse ocular. Telas LCD, amenizam esse incômodo, porém são três vezes mais caras que as convencionais. Outra queixa dos leitores, é que não conseguem abrir mão do contato com o papel, do físico, da comodidade de poder usá-lo em qualquer lugar a qualquer hora e o contato íntimo com o que está escrito.

Os apaixonados por livros impressos, dizem que não há nada que se compare ao cheiro de um livro impresso, poder sentir a sua textura, poder ler o livro em qualquer lugar a qualquer hora ou ainda ter um autógrafo do autor. Segundo Paulino (2009, p. 08) "Este novo modelo de livro promovido por um suporte virtualizador, transformou as relações sensoriais, elementos importantes no processo de leitura. O que antes era entendido como livro cede espaço para uma nova formatação que constitui o não livro. A tela não possibilita a sensação do físico, pelo formato e toque, do manuseio, como o livro tradicional. Não há mais uma relação afetiva; os sentidos não são mais os mesmos aguçados como no livro tradicional, no qual se fazem presentes e bem marcantes o tato, o contato direto com o objeto, a visão, que é atraída pela cor, pelo formato e até o olfato que identifica se o livro tem cheirinho de novo, de velho, etc. No livro eletrônico apenas atua a visão extensivamente."

Acredita-se que se um dia existir só o livro digital, o processo para esse acontecimento será lento e a tecnologia talvez tenha que trazer novidades extraordinárias que consiga fazer com que os livros tradicionais sejam desapegados. Esse processo requer também uma nova aquisição de valores da sociedade, pois para se perder a questão psicológica do contato com o livro, será 
necessário um longo tempo. O fato é que os e-books, facilitaram em alguns casos, mas em outros ainda é impossível facilitar. Cabe aos fornecedores de livros, atender, mesmo que ainda, os dois públicos.

No Brasil, a situação é ainda mais difícil para a popularização dos e-books/e-readers. Os proprietários de tablets no Brasil estão crescendo em ritmo acelerado, no entanto, as ofertas de livros digitais são poucas. Entre os obstáculos que dificultam a expansão desse novo formato de livro são: os direitos autorais e o problema com a pirataria. A venda de livros digitais no Brasil é muito pequena em comparação a venda de impressos. Para a presidente da Câmara Brasileira do Livro (CBL), Karine Pansa, os principais problemas que dificultam o acesso dos leitores aos livros digitais no Brasil é o alto preço dos dispositivos de leitura (tablets e e-readers) e a má qualidade da internet (KONCHINSKI, 2011).

Para Sergio Herz, diretor de operações da Livraria Cultura, e Marcílio Pousada, diretor presidente da Saraiva, um dos maiores desafios para a popularização do livro digital é a falta de um acervo em portugês. Enquanto nos Estados Unidos a Amazon disponibiliza cerca de 2,5 milhões de obras digitais, entre gratuitas e pagas, no Brasil, o número de títulos em português adaptados para o formato eletrônico não passa de 2 mil. Assim, dos 160 mil livros digitais do acervo da editora Saraiva, 158 mil são importados, em inglês. Na livraria cultura, são 110 mil títulos em idioma estrangeiro e perto de dez mil traduzidos.

\subsection{Realidade da educação brasileira}

A educação é o grande pilar para que uma população se desenvolva e progrida a formar cidadãos para o exercício pleno da cidadania, mas não é isso que acontece no Brasil. Infelizmente a educação é tratada com descaso, logo o país não se desenvolve da forma que poderia se desenvolver. A prova do descaso é a falta de bibliotecas em cidades. Apenas um quinto dos municípios brasileiros possuem bibliotecas públicas e as que possuem, muitas vezes estão em estado de má conservação. Considerando a importância da biblioteca para o desenvolvimento cultural de um povo, a inexistência de bibliotecas nas cidades, ou sua existência precária, prejudica o direito dos cidadãos de se formarem leitores, terem acesso às informações e ao patrimônio da cultura humana e desenvolverem competências para obter conhecimento ao longo da vida.

O que se constata em pleno século XXI é um total descaso com a educação brasileira. Muitas escolas estão em estado de horríveis condições, sendo quase que impossível fazer com que os alunos brasileiros se sintam instigados a estudar. Se as escolas já estão em más condições, nem se fala então nas bibliotecas, quando elas existem. Sem citar também, a desvalorização dos 
professores brasileiros, que não possuem salários dignos e boa condições de trabalho. Realmente é um cenário lamentável. Segundo Silva (1999, p. 19) “Podemos afirmar que a biblioteca escolar é um objeto desprezado pela educação, o que se constitui em grande injustiça, posto que a sofrível situação em que funciona, na maioria das escolas, faz com que ela se torne um grave e, vale dizer, inexplorado problema educacional".

Os jovens brasileiros precisam ser instigados a leitura, para assim se tornar algo frequente na vida dos estudantes. É um longo processo de mudança, pois tem de partir das autoridades governamentais, para que haja mobilização e investimentos. A intenção de oferecer suporte na educação, através dos livros é favorecer principalmente aqueles jovens que não tem condições de aquisições, ou qualquer tipo de facilidade de acesso ao conhecimento. Jovens que não tiveram a oportunidade de ter experiências culturais em seu meio social e familiar, com a leitura de revistas, gibis, jornais, artigos, etc.

Esses jovens que começarem a ter acesso a esses materiais, certamente terão mais facilidade de aprendizagem, além dos inúmeros benefícios que a leitura ocasiona na vida de uma pessoa. Segundo Andrade (2002, p. 15) “A biblioteca, instituição milenar que durante séculos garantiu a sobrevivência dos regitros do conhecimento humano tem agora seu potencial reconhecido como partícipe fundamental do complexo processo educacional. Pois pode contribuir efetivamente para preparar crianças e jovens pra viver no mundo contemporâneo, em que a educação e conhecimento assumem destaque central. A biblioteca faz realmente a diferença".

A leitura é algo essencial para o processo de aprendizado dos jovens, por isso deve-se valorizar o livro e a biblioteca - e através destes dar a oportunidade para os jovens e adultos de estar sempre em contato com a cultura. A leitura formal é importante para as crianças e os jovens, para que eles consigam formar referências, e portanto, se tornem capazes de se aprofundar o conhecimento sobre o mundo, assimilinado e analisando os fatos que ocorre durante a vida de modo mais profundo e racional.

E o livro só consegue chegar a esses jovens, através das bibliotecas das escolas, dos centros de educação e dos centros culturais; que são levados a sério, para que no futuro se colham bons frutos. Para esses locais surtirem efeito, precisam possuir aspectos diferentes, que chamem a atenção das crianças e dos jovens, como a tecnologia, cores chamativas, arquitetura moderna, entre outros. 


\subsection{Cultura e artes de Presidente Prudente}

Apesar de Presidente Prudente ser uma cidade com mais de 200 mil habitantes, não possui um cenário cultural e de artes muito relevante. Em relação a esses itens, pode-se citar a existência de dois centros culturais na cidade que proporcionam alguns eventos relacionados, a unidade do SESC (Serviço Social do Comércio) e o centro Cultural Matarazzo, além de alguns serviços oferecidos pela Secretaria de Cultura de Presidente Prudente.

O SESC (Serviço Social do Comérico), oferece diversas atividades culturais e educacionais para a população de Presidente Prudente. Possui na sua infra-estrutura um parque aquático, quadra poliesportiva externa descoberta, sala para ginástica e dança, internet livre com 10 computadores, pista de caminhada (1.000 metros linear), quiosque para atividades, área para convivência, sala de oficinas, cafeteria, central de atendimento, loja Sesc, estacionamento com 20 vagas, odontologia, quadra de areia, espaço para leitura e um espaço para pequenos eventos. $A$ área do seu terreno é de $36.909 \mathrm{~m}^{2}$, possuindo área construída de $2.123 \mathrm{~m}^{2}$. É um local de muita interação para jovens e adultos, possuindo oficinas, shows, esportes e entretenimento, incentivando a cultura e educação entre os prudentinos.

Mantido pela Secretaria de Cultura da cidade, o centro cultural Matarazzo apresenta teatro, galeria, espaço de convivência, auditório, sala de cinema, ateliê de artes visuais, sala de exposições, salas multiuso, estúdio de áudio visual, praça dos Seresteiros, Biblioteca municipal, escola municipal de artes, a própria sede da secretaria municipal de cultura (gabinete e administrativo), Rádio Web Cultura PP, projeto Guri: administrativo, restaurante Delícias da Baby, quiosques e um coreto. É um local também de grande importância para a cidade no âmbito educacional e cultural, afim de propiciar o conhecimento.

\section{CONCLUSÃO}

A questão a ser estudada, é que a educação de Presidente Prudente, pode ser elevada através desse espaço, podendo ser acessado por qualquer pessoa de qualquer idade, contudo destinado principalmente aos jovens. A intenção principal é promover o interesse dos jovens aos livros, seja pelo digital ou físico.

As vantagens dos livros digitais são muito visíveis, porém é preciso concordar que ainda é impossível deixar de ter acesso aos livros físicos. Deixar de ter acesso ao contato físico, visual e olfativo, e abrir mão da intimidade e particularidade do livro, para algumas pessoas é indispensável. 
O livro desempenha um papel muito importante no aprendizado dos jovens, pois, convenhamos que é praticamente impossível ter que aprender a ler e escrever em dispositivos digitais. Isso é muito ilusório, ainda. Temos de ser racionais que a tecnologia é muito importante, porém os métodos considerados por alguns como ultrapassados, ainda não podem ser descartados.

O contato no começo da vida dos seres humanos é muito importante para o desenvolvimento da coordenação motora. Para as crianças, é praticamente nulo visualizar um método de ensino apenas por dispositivos digitais. Outra questão, em relação ao livro digital, é a dificuldade de se fazer pesquisas científicas ou estudos mais complexos. Visto que, dependendo do tamanho e complexidade do conteúdo, se torna cansativo e sem praticidade.

Considerando essas afirmações é possível perceber que o espaço cultural necessita de ambos os livros. Os físicos para as consultas tradicionais e os e-books para as buscas dinâmicas e de interação, deixando claro que ambos são de suma importância para o espaço cultural e artístico.

\section{REFERÊNCIAS}

ANDRADE, M. E. B. A biblioteca faz a diferença. In: CAMPELLO, B. S. et al. A Biblioteca escolar: temas para uma prática pedagógica. Belo Horizonte: Autêntica, 2002.

EPSTEIN, Jason. O Negócio do Livro: Passado, presente e futuro do mercado editorial (Tradução: Zaida Maldonado). Rio de Janeiro: Record, 2002.

KONCHINSKI, Vinicius. Internet lenta e tablet caro travam crescimento de livro digital no país. Agência Brasil de Comunicação, 2011. Disponível em: <http://memoria.ebc.com.br/agenciabrasil/noticia/2011-07-26/intenet-lenta-e-tablet-carotravam-crescimento-de-livro-digtal-no-pais> Acesso em: 15 Abril 2015.

PAULINO, Suzana Ferreira. Livro tradicional $\mathbf{x}$ livro eletrônico: a revolução do livro ou uma ruptura definitiva? Hipertextus, n. 3, 2009. Disponível em: < http://www.hipertextus.net/volume3/SuzanaFerreira-PAULINO.pdf > Acesso em: 03 Junho 2015.

SILVA, W. C. da. Miséria da biblioteca escolar. 2.ed. São Paulo: Cortez, 1999. v.45. 